\title{
Is a Single dose of Prophylactic Antibiotics Sufficient in Patients with Acute Non-Complicated Appendicitis?
}

\author{
Soleiman Hosseini Khalifani ${ }^{1}$, Soleiman Heydari ${ }^{1}$, Mehdi Morshedi ${ }^{1}$, Hassan Ali Mohebi ${ }^{1}$, Gholamali Ghorbani ${ }^{2}$, \\ Shahram Manoochehry ${ }^{3, *}$
}

${ }^{1}$ Department of General Surgery, Faculty of Medicine, Baqiyatallah University of Medical Sciences, Tehran, IR Iran

${ }^{2}$ Baqiyatallah University of Medical Sciences, Tehran, IR Iran

${ }^{3}$ Trauma Research Center, Baqiyatallah University of Medical Sciences, Tehran, IR Iran

*Corresponding Author: Shahram Manoochehry, MD, Trauma Research Center, Baqiyatallah University of Medical Sciences, Tehran, IR Iran. Tel: +98-9122014196, Fax: +98-2181263550, Email: shahram.manoochehry@yahoo.com

Received: 26 May. 2016; Accepted: 13 Jul. 2016; Online Published: 27 Aug. 2016

\begin{abstract}
Background: Acute appendicitis is one of the most common acute surgery events. Its main treatment is surgery. However medical management before and after the surgery has an important impact on the treatment.

Objective: The aim of study was evaluating the outcomes of single dose and quadruple doses of prophylactic antibiotic therapy in patients with acute non-complicated appendicitis.

Methods: This randomized double blind clinical trial was carried out on 294 patients in single dose (136 patients) and the quadruple doses (158 patients) groups. In single dose group, a dose of $1 \mathrm{~g}$ Cefazolin $+500 \mathrm{mg}$ Metronidazole was prescribed intravenously about half an hour before surgery. The quadruple doses group received three more doses after surgery. Two groups were followed for fever, erythema, seroma, wound infection, intra-abdominal abscess formation and readmissions within one month after discharge.

Results: The mean age of patients was $31 \pm 5.14$ years. 203(69\%) of patients were men while $91(31 \%)$ were women. There were no significant statistical differences between groups in age, sex and body mass index (BMI) variables. No significant statistical differences were observed during surgery and hospitalization period between two groups. In the single dose group, wound infection was $8(5.9 \%)$, while it was $6(3.8 \%)$ in the quadruple doses group; hence, there were no significant statistical differences in this regard. There was no abdominal abscess in groups. There were significant statistical differences regarding erythema, seroma and antibiotics consumption costs between groups. Conclusion: A single dose of prophylactic antibiotics is sufficient in patients with acute suppurative non-complicated appendicitis.

Keywords: Appendicitis, Appendectomy, Antibiotic Prophylaxis, Wound Infection, Postoperative Complications
\end{abstract}

\section{Background}

Acute appendicitis is one of the most common acute surgical illnesses and one in every 100,000 people is infected with acute appendicitis. About two third (2/3) of patients are men and two third (2/3) of patients age from 15-44 years old. Nevertheless, anyone can be infected undermining the age $[1,2]$.

One of the stages of acute appendicitis is uncomplicated appendicitis i.e., a hyperemic supportive appendicitis, which is the most prevalent stage in patients diagnosed with appendicitis. Supportive appendicitis is a pathology definition that it is inflamed without gangrene. As a preventive measure for surgical site infections, surgeon tends to prescribe prophylactic antibiotics [1-3].

The major treatment for acute appendicitis is surgery. Occasionally, the diagnosis is complex, and further diagnostic work-up is necessary. Appendectomy is carried out either by means of an open incision or via laparoscopy [1-3].

Medical management before and after the surgery, has an important impact on the treatment. Almost all studies suggest that consumption of antibiotics in acute appendicitis as prophylaxis or as a supplementary treatment in complicated cases (e.g. Perforated, Abscess and Phlegmon) is a proven requirement [1-5].

In acute appendicitis cases that have not received prophylactic antibiotics before surgery, over $25 \%$ wound infection is reported. Antibiotics prescription prior to surgery is considered to be effective in reducing the infectious complications of appendectomy. As a result, most surgeons prescribe antibiotics before surgery for patients diagnosed with appendicitis [1-3, 5-8].

Prescription of antibiotics for the first $24 \mathrm{~h}$ after surgery is only suggested in complicated appendicitis but there is still controversy regarding it [1,9-11].

Sixty percent of intra luminal micro floras aspirated from inflamed appendix are anaerobic bacteria whereas only $25 \%$ of the normal appendix luminal contents are anaerobes and appendicitis is a poly microbial infection [1].

Aerobic flora of the skin alone or with other pathogens leads to a high percentage of surgical site infections. Moreover, gram-negative enteric bacteria are the most probable reasons of wound infection after appendectomy. Cephalosporins have an extended spectrum anti-bacterial effect against gram-positive cocci and gram-negative enteric bacteria and are the most commonly utilized antibiotics in prophylaxis and treatment $[1,3,4]$.

There is controversy regarding prophylactic antibiotics for appendectomy surgery. Some believe that Cefoxitin and Cefotetan are sufficient and some suggest Cefazolin plus metronidazole or Gentamicin plus metronidazole or clindamycin plus metronidazole are best [1, 3, 4, 12-17].

\section{Objective}

Antibiotics prescription after supportive appendicitis surgery requires further study. Regarding the drug side 
effects and microbial resistance to antibiotics due to indiscriminate prescription and regarding economic aspects of their unnecessary usage, we decided to investigate the necessity of antibiotic prescription and evaluate prophylaxis dose in order to distinguish the necessity of antibiotic prescription by means of a prospective randomized clinical trial.

\section{Methods}

This study was a randomized double blind clinical trial. It was carried out on acute appendicitis patients in Baqiyatallah Hospital from March 2014 to January 2016. All patients that voluntarily entered the study signed an informed consent form. This study was approved by the ethics committee of the university.

Inclusion criteria were patients with non-complicated acute appendicitis. Exclusion criteria were: complicated appendicitis, presences of co-morbid diseases, pregnancy, and children below 12-year-old or below $27 \mathrm{~kg}$, age above 70 -year-old, fever over $39{ }^{\circ} \mathrm{C}$, BMI $>40$ or $\mathrm{BMI}<18$ and usage of antibiotics outside the guidelines of the study.

Using a coin flip randomization, patients were divided into two groups of the single dose (136 patients) and the quadruple doses (158 patients) prior to the appendectomy surgery. In single dose group, a dose of $1 \mathrm{~g}$ Cefazolin +500 mg Metronidazole was prescribed intravenously about half an hour before surgery. The quadruple doses group received three more doses every $6 \mathrm{~h}$. No more oral or intravenous antibiotics were prescribed in both groups. Surgeries were carried out by different surgeons. Two groups were followed for wound infection and intra-abdominal abscess formation within one month.

Patients' name, demographics, study group, surgical data, pathology of appendicitis, the method of skin layers repair and type of suture utilized were precisely recorded.

In the first post operation visit (7-10 days after discharge) and the second visit (one month after discharge), patients were examined and asked for the history of postoperative fever, erythema, seroma, positive culture wound infection, intra-abdominal abscess formation and readmissions. Data were analyzed employing SPSS 20 software.

\section{Results}

During the study period, 294 patients were included. The patients were randomly divided into two groups.

Patients' demographics and BMI are shown in Table 1. Patients' demographics and BMI. There were no statistically significant differences between groups in terms of age, sex and BMI.

Table 1. Patients' demographics and BMI

\begin{tabular}{lccc} 
& Single Dose & Quadruple Doses & Total \\
Average Age & $29 \pm 4.22$ & $32 \pm 5.31$ & $31 \pm 5.1$ \\
Sex & & & 0.073 \\
$\quad$ Male & $87(64)$ & $116(73.4)$ & $203(69)$ \\
$\quad$ Female & $49(36)$ & $42(26.6)$ & $91(31)$ \\
Average BMI & $25.32 \pm 3.84$ & $23.82 \pm 3.84$ & $24.79 \pm 4.46$ \\
\hline
\end{tabular}

Data in table are presented as Mean \pm SD or No. $(\%)$.

Table 2. Surgery and hospitalization variables

\begin{tabular}{|c|c|c|c|c|}
\hline & Single Dose & Quadruple Doses & Total & $P$ value \\
\hline \multicolumn{4}{|l|}{ Incision } & \multirow{3}{*}{0.999} \\
\hline M & $100(73.5)$ & $116(73.4)$ & $216(73.5)$ & \\
\hline $\mathrm{R}$ & $36(26.5)$ & $42(26.6)$ & $78(26.5)$ & \\
\hline \multicolumn{4}{|l|}{ Fascia and muscle repair yarn } & \multirow{3}{*}{0.463} \\
\hline V & $30(22.1)$ & $28(18.2)$ & $58(19.7)$ & \\
\hline $\mathrm{C}$ & $106(77.9)$ & $126(81.8)$ & $232(78.9)$ & \\
\hline \multicolumn{4}{|l|}{ Skin suture material } & \multirow{3}{*}{0.001} \\
\hline $\mathrm{N}$ & $126(92.6)$ & $124(79.5)$ & $250(85)$ & \\
\hline Mo & $10(7.4)$ & $34(20.5)$ & $44(14.9)$ & \\
\hline \multicolumn{4}{|l|}{ Subcutaneous closure } & \multirow{3}{*}{0.001} \\
\hline Has & $65(49.2)$ & $40(25.3)$ & $105(35.7)$ & \\
\hline Does not have & $67(50.8)$ & $118(74.7)$ & $185(62.9)$ & \\
\hline Average surgery time (minutes) & $46.63 \pm 13.81$ & $45.22 \pm 13.40$ & $45.85 \pm 13.52$ & 0.294 \\
\hline Average hospitalization time (hours) & $34.5 \pm 7.02$ & $35.56 \pm 6.90$ & $35.96 \pm 6.96$ & 0.595 \\
\hline \multicolumn{4}{|l|}{ Pathology } & \multirow{4}{*}{0.320} \\
\hline Normal & $8(5.9)$ & $4(2.5)$ & $12(4.08)$ & \\
\hline Inflammatory & $32(23.5)$ & $42(26.6)$ & $72(24.4)$ & \\
\hline Suppurative & $96(70.6)$ & $112(70.9)$ & $208(70.7)$ & \\
\hline
\end{tabular}

M=Mac Burnie, $\mathrm{R}=$ Rocky Davis, V=Vicryl, $\mathrm{C}=$ Chromic, $\mathrm{N}=$ Nylon, $\mathrm{MO}=$ Mono Creel

Table 3. Post-surgical events

\begin{tabular}{|c|c|c|c|c|c|}
\hline Study Group & Erythema & Seroma & Fever & Wound Infection & Abdominal Abscess \\
\hline Single dose & $42(30.9)$ & $32(23.5)$ & $8(5.9)$ & $8(5.9)$ & 0 \\
\hline Quadruple doses & $26(16.5)$ & $12(7.6)$ & $6(3.8)$ & $6(3.8)$ & 0 \\
\hline Total & $68(23.1)$ & $44(14.9)$ & $14(4.7)$ & $14(4.7)$ & 0 \\
\hline$P$ value & 0.004 & 0.001 & 0.425 & 0.425 & 0 \\
\hline
\end{tabular}


Surgery and hospitalization variables are shown in Table 2. The number of appendectomies in men was twice that of women, and the highest incidence of appendectomies were seen in the age category of 20-35. There were no statistically significant differences in surgery time, hospitalization time, surgical incision type (Mac Burnie vs. Rocky Davis) and pathology type (normal, inflammatory, supportive).

There were no statistically significant differences in type of suture materials used for fascia and muscle repair between groups. However, there were statistically significant differences in terms of subcutaneous closure, the type of the suture material utilized for subcutaneous repair, and the suture type utilized for skin repair. Table 3 shows the Postsurgical events of our study.

There was statistically significant difference in seroma in the first ten days of survey between groups.

There was no statistically significant difference in erythema in the first ten days of survey between groups.

There were no statistically significant differences in both wound infection and intra-abdominal abscess between groups. Antibiotics cost of the quadruple doses group was four times the single dose group.

\section{Discussion}

Despite significant developments in diagnostic tools, early operation in cases suspected to be more than $70-85 \%$ appendicitis using the clinical history, physical examination and initial Para clinic tests is necessary [1]. When the surgeon decides to operate the patient, prescribing adequate intravenous fluids, correction of electrolyte abnormalities and proper management of kidney, as well as heart and lung problems should be considered. Majority of the studies consider antibiotics after surgery for complicated appendicitis, which is necessary and effective in reducing abdominal and pelvic abscess. Nevertheless, it is not necessary to continue antibiotic therapy after proper drainage and irrigation of superficial wound infection [1-3, 5].

Fever and wound infection in the quadruple doses group of our study was lower than the single dose group, nevertheless, there were no statistically significant differences $(\mathrm{P}=0.425)$ and these results were similar to those of other studies $[4,9,16-20]$.

Therefore, it does not seem that antibiotic therapy has any effect on the reduction of wound infection. There were statistically significant differences in erythema and seroma between two groups, and these were higher in quadruple doses group. However, this should not be related to the antibiotic effect because wound infection and fever and abdominal abscess did not have statistically significant differences, and there could be other causes for erythema and seroma in single dose group.

In this study, there was no statistically significant difference between groups $(\mathrm{P}=0.294)$, in terms of hospital stay of the patients after surgery which is similar to the results of other studies [4, 9, 15, 17-19].

It should be noted that acute appendicitis occurs in young and middle age groups and often patients are healthy people without underlying disease; so, feeding and hospital discharge is possible after a short period after surgery. In this study, antibiotic consumption after surgery did not have any particular effects in patient discharge delay.

\section{Conclusion}

As superficial and deep wound infection in both groups of our study were not statistically significant, and as costs in the single dose group is less than the quadruple doses group, prescription of a single dose of prophylactic antibiotics prior to surgery of uncomplicated acute appendicitis is sufficient.

\section{Acknowledgements}

This study was conducted as a thesis. We would like to thank the "Clinical Research Development Unit" of Baqiyatallah Hospital for their kind cooperation. Also, the authors wish to thanks the Mr. Hamid Reza Rasouli for his kindly advises.

\section{Authors' Contributions}

Study concept and design: SHK, SH, MM, HAM and GG. Analysis and interpretation of data: SHK, SH and SM. Drafting of the manuscript: SHK and SM. Technical and material support: SHK, SH, MM and GG. Study supervision: $\mathrm{SH}, \mathrm{MM}, \mathrm{HAM}$ and GG.

\section{Conflict of Interest}

None.

\section{References}

1. Brunicardi F, Anderson D, Billiar T, Dunn D, Hunter J, Pollock RE et al. Schwartzs Current Practice of General Surgery (EBOOK): McGraw Hill Professional; 2014.

2. Townsend Jr CM, Beauchamp RD, Evers BM, Mattox KL. Sabiston textbook of surgery: Elsevier Health Sciences; 2012.

3. Ashley SW, Zinner M. Maingot's abdominal operations: McGrawHill Publishing; 2007.

4. Mason RJ, Moazzez A, Sohn H, Katkhouda N. Meta-analysis of randomized trials comparing antibiotic therapy with appendectomy for acute uncomplicated (no abscess or phlegmon) appendicitis. Surg Infect (Larchmt). 2012;13(2):74-84. doi: 10.1089/sur.2011.058

5. Hawkins RB, Levy SM, Senter CE, Zhao JY, Doody K, Kao LS, et al. Beyond surgical care improvement program compliance: antibiotic prophylaxis implementation gaps. Am J Surg. 2013;206(4):451-6. doi: 10.1016/j.amjsurg.2013.02.009

6. Wray CJ, Kao LS, Millas SG, Tsao K, Ko TC. Acute appendicitis: controversies in diagnosis and management. Curr Probl Surg. 2013;50(2):54-86. doi: 10.1067/j.cpsurg.2012.10.001

7. Coakley BA, Sussman ES, Wolfson TS, Bhagavath AS, Choi JJ, Ranasinghe NE, et al. Postoperative antibiotics correlate with worse outcomes after appendectomy for nonperforated appendicitis. J Am Coll Surg. 2011;213(6):778-83. doi 10.1016/j.jamcollsurg.2011.08.018

8. Enzler MJ, Berbari E, Osmon DR, editors. Antimicrobial prophylaxis in adults. Mayo Clinic Proceedings; 2011: Elsevier.

9. Daskalakis K, Juhlin C, Påhlman L. The use of pre-or postoperative antibiotics in surgery for appendicitis: a systematic review. Scand J Surg. 2014;103(1):14-20. doi: 10.1177/1457496913497433

10. Wu W-T, Tai F-C, Wang P-C, Tsai M-L. Surgical Site Infection and Timing of Prophylactic Antibiotics for Appendectomy. Surg Infect (Larchmt). 2014;15(6):781-5. doi: 10.1089/sur.2013.167

11. Bratzler DW, Dellinger EP, Olsen KM, Perl TM, Auwaerter PG, Bolon MK, et al. Clinical practice guidelines for antimicrobial prophylaxis in surgery. Am J Health Syst Pharm. 2013;70(3):195283. doi: 10.2146/ajhp120568

12. Andersen BR, Kallehave FL, Andersen HK. Antibiotics versus placebo for prevention of postoperative infection after appendicectomy. Cochrane Database Syst Rev. 2005;3:CD001439. doi: 10.1002/14651858.cd001439.pub2

13. Solomkin JS, Mazuski JE, Bradley JS, Rodvold KA, Goldstein EJ, Baron EJ, et al. Diagnosis and management of complicated intraabdominal infection in adults and children: guidelines by the Surgical Infection Society and the Infectious Diseases Society of America. Surg Infect (Larchmt). 2010;11(1):79-109. doi: 10.1089/sur.2009.9930

14. Khan MN, Fayyad T, Cecil TD, Moran BJ. Laparoscopic versus open appendectomy: the risk of postoperative infectious complications. JSLS. 2007;11(3):363.

15. Kasatpibal N, Nørgaard M, Sørensen HT, Schønheyder HC, Jamulitrat S, Chongsuvivatwong V. Risk of surgical site infection and efficacy of antibiotic prophylaxis: a cohort study of appendectomy patients in Thailand. BMC Infect Dis. 2006;6:111. 
doi: 10.1186/1471-2334-6-111

16. Liberman MA, Greason KL, Frame S, Ragland JJ. Single-dose cefotetan or cefoxitin versus multiple-dose cefoxitin as prophylaxis in patients undergoing appendectomy for acute nonperforated appendicitis. J Am Coll Surg. 1995;180(1):77-80.

17. Mui LM, Ng CS, Wong SK, Lam YH, Fung TM, Fok KL, et al. Optimum duration of prophylacticantibiotics in acute non-perforated appendicitis. ANZ J Surg. 2005;75(6):425-8. doi: 10.1111/j.14452197.2005.03397.x

18. Hussain MI, Alam MK, Al-Qahatani HH, Al-Akeely MH. Role of postoperative antibiotics after appendectomy in non-perforated appendicitis. J Coll Physicians Surg Pak. 2012;22:756-9.

19. Ravari H, Jangjoo A, Motamedifar J, Moazzami K. Oral metronidazole as antibiotic prophylaxis for patients with nonperforated appendicitis. Clin Exp Gastroenterol. 2011;4:273. doi: 10.2147/CEG.S18153

20. Ali K, Latif H, Ahmad S. Frequency of wound infection in nonperforated appendicitis with use of single dose preoperative antibiotics. J Ayub Med Coll Abbottabad. 2015;27(2):378-80. 